\title{
Papilledema, CTCAE
}

National Cancer Institute

\section{Source}

National Cancer Institute. Papilledema, CT CAE. NCI Thesaurus. Code C143734.

A disorder characterized by swelling around the optic disc. 